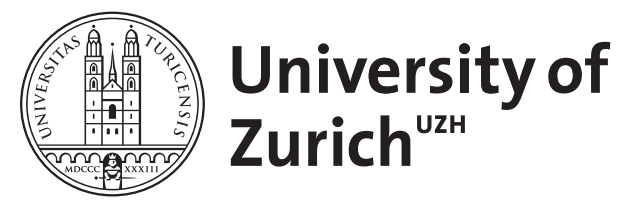

\title{
On being small: brain allometry in ants
}

\author{
Wehner, R ; Fukushi, T ; Isler, K
}

\begin{abstract}
Comparative neurobiologists have provided ample evidence that in vertebrates small animals have proportionally larger brains: in a double-logarithmic plot of brain weight versus body weight all data points conform quite closely to a straight line with a slope of less than one. Hence vertebrate brains scale allometrically, rather than isometrically, with body size. Here we extend the phylogenetic scope of such studies and the size range of the brains under investigation to the insects, especially ants. We show that the principle of (negative) allometry applies as well, but that ants have considerably smaller brains than any ant-sized vertebrate would have, and that this result holds even if the relatively higher exoskeleton weights of ants (as compared to endoskeleton weights of mammals) are taken into account. Finally, interspecific comparisons within one genus of ants, Cataglyphis, show that species exhibiting small colony sizes (of a few hundred individuals) have significantly smaller brains than species in which colonies are composed of several thousand individuals.
\end{abstract}

DOI: https://doi.org/10.1159/000097057

Posted at the Zurich Open Repository and Archive, University of Zurich

ZORA URL: https://doi.org/10.5167/uzh-379

Journal Article

Published Version

Originally published at:

Wehner, R; Fukushi, T; Isler, K (2007). On being small: brain allometry in ants. Brain, Behavior and Evolution, 69(3):220-228.

DOI: https://doi.org/10.1159/000097057 


\title{
On Being Small: Brain Allometry in Ants
}

\author{
Rüdiger Wehner ${ }^{a}$ Tsukasa Fukushic ${ }^{c}$ Karin Isler ${ }^{b}$ \\ ${ }^{\mathrm{a}}$ Institute of Zoology and ${ }^{\mathrm{b}}$ Anthropological Institute and Museum, University of Zürich, Zürich, Switzerland; \\ 'Department of Biology, Miyagi University of Education, Aramaki-aza-Aoba, Aoba-ku, Sendai, Japan
}

\section{Key Words}

Allometry $\cdot$ Brain size $\cdot$ Formicidae $\cdot$ Cataglyphis $\cdot$ Insects • Invertebrates

\begin{abstract}
Comparative neurobiologists have provided ample evidence that in vertebrates small animals have proportionally larger brains: in a double-logarithmic plot of brain weight versus body weight all data points conform quite closely to a straight line with a slope of less than one. Hence vertebrate brains scale allometrically, rather than isometrically, with body size. Here we extend the phylogenetic scope of such studies and the size range of the brains under investigation to the insects, especially ants. We show that the principle of (negative) allometry applies as well, but that ants have considerably smaller brains than any ant-sized vertebrate would have, and that this result holds even if the relatively higher exoskeleton weights of ants (as compared to endoskeleton weights of mammals) are taken into account. Finally, interspecific comparisons within one genus of ants, Cataglyphis, show that species exhibiting small colony sizes (of a few hundred individuals) have significantly smaller brains than species in which colonies are composed of several thousand individuals.

Copyright $\odot 2007$ S. Karger AG, Basel
\end{abstract}

\section{Introduction}

Ever since Jerison's [1973] comparative account of the evolution of brains it has been well established that brain size scales with body size across large groups of vertebrates. By correlating brain mass $\mathrm{M}_{\text {brain }}$ to body mass $\mathrm{M}_{\text {body }}$ via the allometric formula $\mathrm{M}_{\mathrm{brain}}=\mathrm{a} \cdot \mathrm{M}_{\mathrm{body}} \mathrm{b}$ several studies have shown that in mammals [Martin, 1981, 1983] the scaling exponent is close to $b=0.75$ and thus very similar to the value with which basal metabolic rate scales to body mass [Kleiber, 1961; Taylor et al., 1982], whereas reptiles and birds exhibit allometric exponents that are considerably smaller [b about 0.56; Martin, 1981]. The question of how to interpret these values in functional terms has fueled some quite animated discussions [Harvey and Pagel, 1991; Martin, 1996], but a general answer is not yet available.

Arthropods and vertebrates are separate evolutionary success stories [Hölldobler and Wilson, 1990; Nielsen, 2001; Hildebrand and Goslow, 2001]. In phylogenetic terms their last common ancestor dates all the way back into Precambrian times [Benton and Ayala, 2003; Chen et al., 2004; Peterson et al., 2004]. However, as shown by recent molecular studies, in the developing central nervous system of insects and vertebrates there are orthologous regulatory genes, e.g., genes of the homeotic complex, that exhibit similar spatio-temporal expression pat-

Prof. Dr. Rüdiger Wehner

Department of Zoology

University of Zürich, Winterthurerstrasse 190

CH-8057 Zürich (Switzerland)

Tel. +41 4463 54831, Fax +41 4463 55716, E-Mail rwehner@zool.unizh.ch 
terns [Sharman and Brand, 1998; Williams and Hollard, 1998; Reichert and Simeone, 1999] and thus define comparable segmentation events in the embryonic development of insect and vertebrate brains [Strausfeld, 2001]. Irrespective of how far the later developmental pathways have diverged in both groups of animals, the brains that have resulted differ in at least one global aspect: their size. The brain of an ant is three orders of magnitude smaller than the brain of the smallest mammal studied in this context, the bat Tylonycteris pachypus, with a brain mass of $0.074 \mathrm{~g}$ [Stephan et al., 1981].

There are only a few published cases in which the sizes of insect brains have been inferred from data obtained in the context of physiological measurements [Kern, 1985] or computed from histological sections [Goossen, 1949; Neder, 1959; Korr, 1968; Jaffe and Perez, 1989; Gronenberg and Hölldobler, 1999]. These data refer to adults of various taxa of holometabolic insects such as orthopterans, coleopterans, and hymenopterans [Goossen, 1949; Kern, 1985; Jaffe and Perez, 1989; Gronenberg and Hölldobler, 1999; Ehmer et al., 2001] and to different ontogenetic stages of apterygote or hemimetabolic insects [collemboles, Korr, 1968; and cockroaches, Neder, 1959, respectively]. Taken together, however, they do not yet enable us to derive a common allometric function, because in the various studies cited above different parts of the brain were investigated (e.g., including or excluding the suboesophageal ganglion or considering only particular areas of the brain), different volumetric measures and weighing procedures were applied, and different (intra- or interspecific) comparisons have been made.

A recent upsurge of interest in the morphometrics of insect brains has been caused by the observation that in the brains of social hymenopterans volumetric changes of certain neuropiles occur during both phylogenetic [Gronenberg and Hölldobler, 1999; Ehmer et al., 2001] and ontogenetic time [Durst et al., 1994; Gronenberg et al., 1996; Fahrbach et al., 1998, 2003; Gronenberg and Liebig, 1999; Farris et al., 2001; Brown et al., 2004; O'Donnell et al., 2004]. For example, the mushroom bodies, which are regarded as multimodal sensory integration centers [Gronenberg, 1987; Li and Strausfeld, 1997; Strausfeld et al., 1998] involved in learning and memory [Connolly et al., 1996; Heisenberg, 1998; Strausfeld et al., 1998], exhibit marked differences in the relative sizes of their olfactory and visual input regions (lip and collar, respectively) in species of ants with different life styles [Gronenberg and Hölldobler, 1999; Ehmer and Gronenberg, 2004]. Age-related and task-dependent changes have been observed within the mushroom bodies of a va- riety of eusocial hymenopterans [bees: Durst et al., 1994; Fahrbach et al., 1998, 2003; Farris et al., 2001; ants: Gronenberg, et al., 1996; Gronenberg and Liebig, 1999; Kuehn-Buehlmann and Wehner, 2006; wasps: O'Donnell et al., 2004] and, to a certain degree, in Drosophila as well [Barth and Heisenberg, 1997]. All these recent studies on the long-term and short-term adaptive plasticity of insect brains have certainly stimulated, though not directly addressed, the question of how insect brains scale with body size, and have emphasized the need to introduce allometric approaches to the study of brain-body relationships in insects.

\section{Materials and Methods}

\section{Animals}

Ant workers of various species of the North African genus Cataglyphis were collected in the Tunisian Sahel region at Maharès $\left(34.58^{\circ} \mathrm{N}, 10.50^{\circ} \mathrm{E}\right.$ : C. bicolor and C. fortis), at Soliman $\left(36.72^{\circ}\right.$ $\mathrm{N}, 11.50^{\circ} \mathrm{E}$ : C. viatica) and in the Tunisian highland steppes at Kasserine $\left(35.12^{\circ} \mathrm{N}, 8.73^{\circ} \mathrm{E}\right.$ : C. mauritanica). C. aenescens belonging to the ancestral cursor species group came from the southern Gobi desert (Dalanzadgad/Mongolia: $43.58^{\circ} \mathrm{N}, 104.42^{\circ}$ E). Foragers of the Japanese species Camponotus japonicus, C. obscripes, Formica japonica, Lasius nipponensis, and L. umbratus were captured near Sendai $\left(38.16^{\circ} \mathrm{N}, 140.52^{\circ} \mathrm{E}\right)$.

\section{Isolation of Brains}

Ants were first immobilized with nitrogen gas, and their body mass was measured by using chemical or semimicro balances (Mettler HK 16 and Mettler Toledo AT 460 or AG 245). The head was then cut off, transferred to insect Ringer solution, and dissected by forceps under a dissection microscope (Wild Heerbrugg M7, Olympus X2). The brain including the suboesophageal ganglion and the optic lobes (but not the retinae) was separated from all tracheae and connective tissues and removed from the head capsule. Even though in many arthropod studies the term brain refers only to the supra-oesophageal part of the central nervous system, the suboesophageal ganglion was included here due to its partial functional equivalence with the vertebrate hind brain. Hence, in the present account on ants the brain constitutes the entire encephalized part of the central nervous system just as it does in vertebrates. The brain was isolated by using a pair of scissors to cut the nerves that connected the brain with the remainder of the nervous system at their roots less than $0.1 \mathrm{~mm}$ from their origins at the brain. The isolated brain was lifted up into the air by using a tungsten hook inserted in the oesophageal foramen. The Ringer solution was removed from the surface of the brain by touching the brain with a piece of filter paper. Afterwards the brain was dropped into a hemispherical plastic dish $(20 \mathrm{~mm}$ wide and $10 \mathrm{~mm}$ deep, in the following referred to as the 'weighing dish') which was filled with three drops of paraffin oil (Erne-Chemie Co. or Wako Pure Chemical Industries). The brain immediately sank to the bottom of the pool of oil, where it was protected from evaporative water loss. 
Measurement of Brain Mass

The weight of the weighing dish was recorded before and after loading it with the ant's brain (microbalances Mettler ME30, Mettler Toledo MX5 and Jupiter M1-20). The difference between the two measurements indicates the mass of the brain. In the time interval between removal of the isolated brain from the Ringer solution and embedding the brain in the oil pool, the brain was exposed to air for about $30 \mathrm{~s}$. It hence suffered from some, albeit limited, water loss. To correct for this effect, the time course of the decrease in the mass of the brain exposed to air was measured over a time period of $3 \mathrm{~min}$, during which there was a linear decrease in brain mass $\left(\mathrm{M}_{\text {brain, } 3 \mathrm{~min}}=-0.077 \mathrm{M}_{\text {brain, } 0 \mathrm{~min}}+1.002\right)$. The mass of each brain measured as described above was then corrected for the water loss during the 30-second period of handling the brain in the air $(3.87 \pm 0.38 \%$ (mean \pm SD) of brain mass at time $0 \mathrm{~min})$.

\section{Isolation and Weighing of Exoskeleton}

Freshly killed ants were boiled in a $1 \%$ solution of detergent (Handy, Migros Co., Switzerland) for $5 \mathrm{~min}$ each and dissected while still submerged within the detergent solution. After the ants' bodies had been broken up into 45-80 fragments, all soft tissues were removed from the exoskeleton fragments. Antennae, tarsi, maxillary and labial palps were not dissected but left intact. The endoskeletons of the head (the tentorium) and of the prothorax (the endosternites) were isolated and combined with other exoskeletal parts. All skeleton fragments of each ant were cleaned with the detergent solution, then transferred to distilled water and finally to filter paper to remove the adherent water.

The weighing procedure was exactly the same as described above for the brain measurements. However, in order to allow for desiccation, the weighing dish loaded with the skeleton fragments was placed in the laboratory room for $16-18 \mathrm{~h}$ before weight measurements were taken. This time period was sufficiently long for almost complete desiccation to occur, because measuring the same samples 2 to 14 days later did not result in any further water loss ( $\mathrm{p}>0.1, \mathrm{n}=14$, Wilcoxon paired-sample test).

\section{Statistics}

The choice of an appropriate method for fitting a regression line to data is one of the major problems in bivariate allometric analysis. For intraspecific data, a bivariate normal distribution is commonly assumed, and ordinary least-squares regression is usually applied. For interspecific data, however, we prefer a nonparametric alternative, the 'rotation method' [Martin and Barbour, 1989; Isler et al., 2002], which requires neither an assumption about the distribution of the data nor an estimation of the error variances. It is symmetrical in the two variables and highly resistant against the influence of outlying data points, thus combining the advantages of robust regression techniques and major axis regression. However, as the resulting lines are all quite similar to the least-squares regressions, the brain-body relationships of ants, birds, reptiles and mammals were compared with an analysis of covariance (ANCOVA).

Because of their shared ancestry, species do not necessarily represent independent data points in interspecific analyses [Harvey and Pagel, 1991]. This potential problem of 'phylogenetic nonindependence' can be offset by using the method of independent contrasts [Felsenstein, 1985; Harvey and Pagel, 1991], in which only independent evolutionary events are considered.
Table 1. Phylogeny used for CAIC [Purvis and Rambaut, 1995]

\begin{tabular}{lll}
\hline Node & Species & Branch length \\
\hline A & & 27 \\
AA & Camponotus japonicus & 39 \\
AB & Camponotus obscuripes & 40 \\
B & & 14 \\
BA & Cataglyphis cursor & 2 \\
BAA & Cataglyphis mauritanica & 28 \\
BAB & & 21 \\
BAC & Cataglyphis fortis & 12 \\
BACA & & 10 \\
BACB & Cataglyphis viatica & 13 \\
BACBA & Cataglyphis bicolor & 12 \\
BACBB & & 11 \\
BB & & 25 \\
BBA & Lasius umbratus & 23 \\
BBAA & Lasius nipponensis & 20 \\
BBAB & Formica japonica & 41 \\
BBB &
\end{tabular}

\section{Molecular Systematics}

Based on an analysis of mitochondrial DNA (cytochrome oxidase 1, 360 base pairs), a phylogenetic tree of the ant species involved in this study was determined (see table 1). Some ant species had to be replaced by closely related species: Formica lefrancoisi instead of F. japonica, Lasius flavus instead of L. umbratus, Lasius fuliginosus instead of L. nipponensis, Camponotus ruficaudatus instead of C. obscuripes. From this tree, eight independent nodes were calculated by the CAIC computer program [version 2.6.9; Purvis and Rambaut, 1995], and a regression line was forced through the origin. It has been stated that the expected value of the slope of this line equals the true relation between the original variables in the absence of phylogenetic effects [Pagel, 1993].

\section{Results}

The brains of 247 specimens from 10 species of ants were dissected out of their head capsules. They consisted of the protocerebrum, deutocerebrum and tritocerebrum as well as the suboesophageal ganglion, i.e., of the entire central nervous system residing within the head capsule. In figure 1 the brain-body relationships of five species of Cataglyphis ants are shown. The scaling exponents for the intraspecific comparisons range from $b=0.203$ to 0.420 (table 2). Correlating mean brain mass (g) and body mass (g) for all 10 species yields the following allometric formula [nonparametric method: rotation line; Isler et al., 2002]:

$$
\ln \mathrm{M}_{\text {brain }}=0.567 \ln \mathrm{M}_{\text {body }}-6.112
$$


Table 2. Relationship between brain and body mass in 10 ant species
Least-squares regression of brain mass (mg) vs. body mass (mg)

\begin{tabular}{llllll}
\hline Species & $\mathrm{n}$ & Slope & $\mathrm{y}$-intercept & $\mathrm{R}^{2}$ & p value of slope \\
\hline Cataglyphis bicolor & 58 & 0.420 & -2.616 & 0.870 & $<0.001$ \\
Cataglyphis mauritanica & 35 & 0.402 & -2.689 & 0.927 & $<0.001$ \\
Cataglyphis viatica & 17 & 0.388 & -2.535 & 0.954 & $<0.001$ \\
Camponotus japonicus & 58 & 0.289 & -2.111 & 0.894 & $<0.001$ \\
Camponotus obscuripes & 11 & 0.203 & -1.753 & 0.619 & 0.004 \\
Formica japonica & 23 & 0.327 & -2.561 & 0.628 & $<0.001$ \\
\hline
\end{tabular}

Mean \pm 1 standard deviation

\begin{tabular}{lrlc}
\hline Species & $\mathrm{n}$ & Brain mass $(\mathrm{mg})$ & Body mass $(\mathrm{mg})$ \\
\hline Cataglyphis aenescens & 9 & $0.102 \pm 0.010$ & $7.529 \pm 2.068$ \\
Cataglyphis fortis & 11 & $0.170 \pm 0.011$ & $23.491 \pm 2.237$ \\
Lasius nipponensis & 9 & $0.098 \pm 0.003$ & $4.969 \pm 0.558$ \\
Lasius umbratus & 5 & $0.096 \pm 0.003$ & $3.950 \pm 0.343$
\end{tabular}

Those species of ants for which the slope of the best-fit line is significantly different from zero are depicted in the upper part of the table. The lower part of the table presents mean values and standard deviations for species in which the sample size or the variation in body size is small, so that the slope of the best-fit line does not significantly differ from zero. $(\mathrm{r}=0.783,95 \%$ confidence limits for $\mathrm{b}=0.329-0.931$; fig. 2). Applying the Independent Contrasts Method yields a very similar brain-body size relationship $(\mathrm{b}=$ $0.539, \mathrm{p}<0.01$, least-squares regression forced through the origin). For comparison, representative examples of data from 474 mammalian species [von Bonin, 1937; Count, 1947; Crile and Quiring, 1940; Stephan et al., 1970; Martin, 1981], 201 avian species [Crile and Quiring, 1940; Portmann, 1947; Boire and Baron, 1994], and 65 reptilian species [Crile and Quiring, 1940; Platel, 1976] were used to compute allometric equations for mammals (II), birds (III), and reptiles (IV) by applying the same nonparametric computational method as in ants:

$$
\begin{aligned}
& \ln \mathrm{M}_{\text {brain }}=0.773 \ln \mathrm{M}_{\text {body }}-3.079 \\
& \ln \mathrm{M}_{\text {brain }}=0.576 \ln \mathrm{M}_{\text {bdy }}-2.107 \\
& \ln \mathrm{M}_{\text {brain }}=0.540 \ln \mathrm{M}_{\text {body }}-4.077
\end{aligned}
$$

(rotation line; mammals, equation (II): $\mathrm{r}=0.969,95 \%$ confidence limits for $\mathrm{b}=0.762-0.789$; birds, equation (III): $\mathrm{r}=0.851,95 \%$ confidence limits for $\mathrm{b}=0.532-0.608$; reptiles, equation (IV): $r=0.909,95 \%$ confidence limits for $b=0.477-0.598$; fig. 2).

What is immediately apparent from the equations (I)(IV) and figure 2 is that the best-fit line for the ant data lies significantly lower than the lines for mammals, birds or reptiles (ANCOVA, both $\mathrm{p}<0.001$ ). This result means that the brains of ants are smaller (if compared to body size) than the brain of any hypothetical ant-sized reptile, bird, or mammal. The second observation that in ants, birds, and reptiles the allometric scaling exponent $b$ almost coincides should not be overemphasized. The $95 \%$ confidence limits on the values for ants are very wide indeed, and include the value for mammals as well.

However, are the brains of ants, when allometrically adjusted for body size, really smaller than the brains of the terrestrial vertebrates mentioned above, or is some other component of body mass disproportionately larger in ants than it is in vertebrates? The most obvious component to be considered in this context is certainly the exoskeleton of insects as compared to the endoskeleton of vertebrates. As one can compute by using the data provided by Prange et al. [1979], in mammals (V) and birds (VI), endoskeleton mass $M_{\text {endo }}$ scales with body mass $\mathrm{M}_{\text {body }}$ with the following allometric functions:

$$
\begin{aligned}
& \ln \mathrm{M}_{\text {endo }}=1.015 \ln \mathrm{M}_{\text {body }}-2.994 \\
& \ln \mathrm{M}_{\text {endo }}=1.078 \ln \mathrm{M}_{\text {body }}-3.222
\end{aligned}
$$

(rotation line; mammals, equation $(\mathrm{V}): \mathrm{r}=0.987,95 \%$ confidence limits for $b=0.983-1.051$; birds, equation $(\mathrm{VI}): \mathrm{r}=0.987,95 \%$ confidence limits for $\mathrm{b}=1.053-1.099$; fig. 3). For the exoskeletons of insects comparable data are not yet available; hence, we measured the exoskeleton 


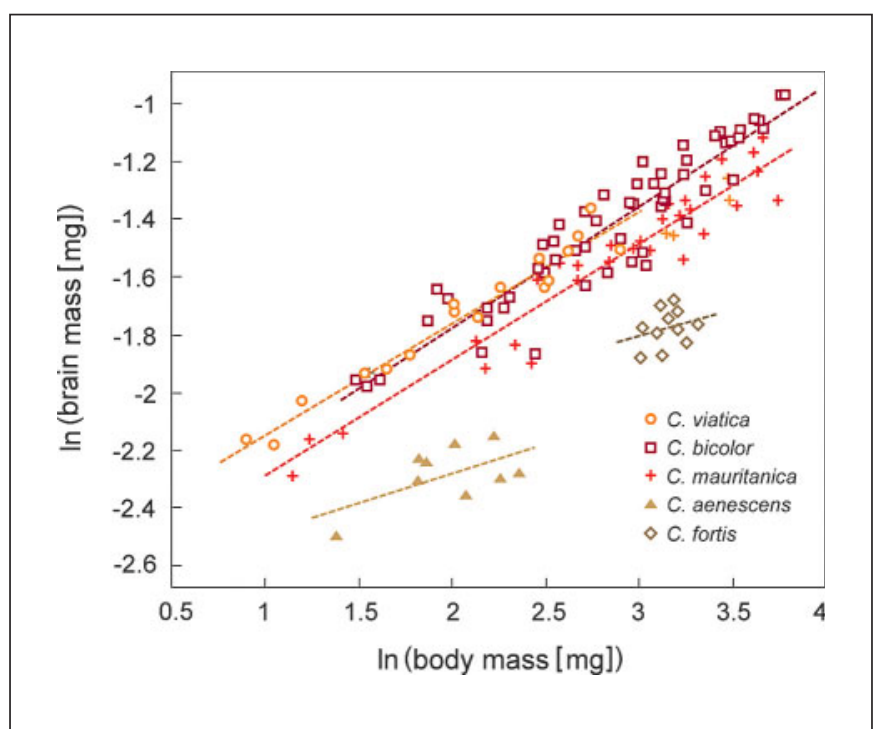

Fig. 1. Brain-body mass allometry in five species of Cataglyphis ants. See also table 2. mass of 27 differently sized specimens of the ant species Cataglyphis bicolor and Camponotus japonicus after having dissected the bodies of the ants into several dozen fragments, from which we had removed all soft body tissues (see Methods). The allometric best-fit line for the exoskeleton-body size relationship of ants

$$
\ln \mathrm{M}_{\text {exo }}=1.244 \ln \mathrm{M}_{\text {body }}-1.122
$$

(least-squares regression; $\mathrm{r}=0.986,95 \%$ confidence limits for $\mathrm{b}=1.182-1.305$; fig. 3 ) lies well above the endoskeleton-body size relationship of mammals and birds and has a much higher slope. The latter finding is in agreement with results obtained for spiders, in which the scaling exponent of the exoskeleton-body size relationship is also significantly larger than $1.0[\mathrm{~b}=1.135$; Anderson et al., 1979].

When compared with the brain-body size relationships shown in figure 2, the result of the exoskeleton measurements could mean that ants do not have allometrically

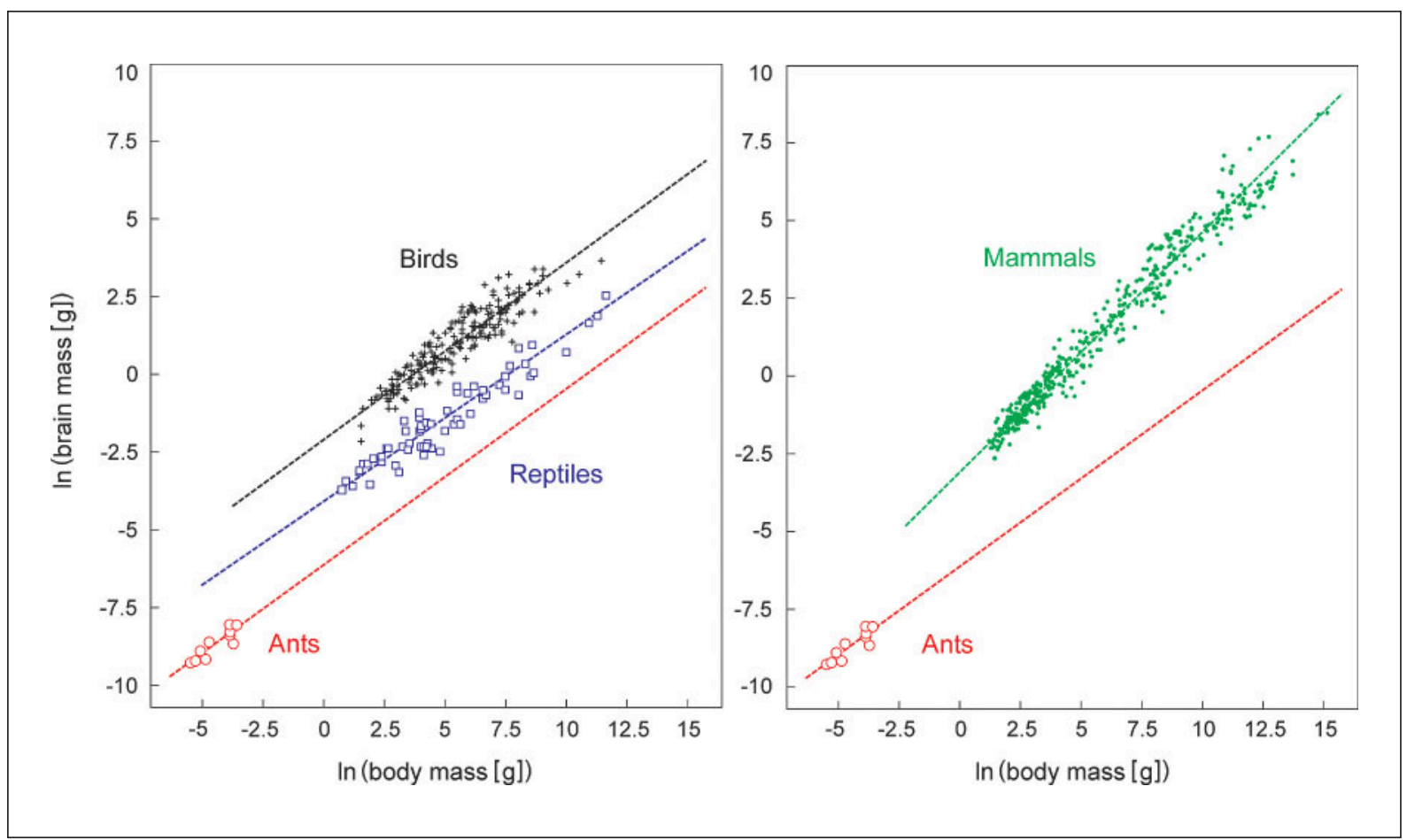

Fig. 2. Brain-body mass allometry in ants and terrestrial vertebrates (mammals, birds, reptiles). The data for 10 species of ants are based on measurements obtained in $23.6 \pm 20.1$ (mean \pm SD) individuals per species, whereas in mammals (right figure), birds and reptiles (left figure) the data mostly refer to single individuals per species. All the regression lines (for equations see text) were calculated by applying the robust method of the rotation line to the ant data obtained in the present account and to the vertebrate data taken from the literature [mammals: Crile and Quiring, 1940; Martin, 1981; birds: Crile and Quiring, 1940; Portmann, 1947; Boire and Baron, 1994; reptiles: Crile and Quiring, 1940; Platel, 1976]. 


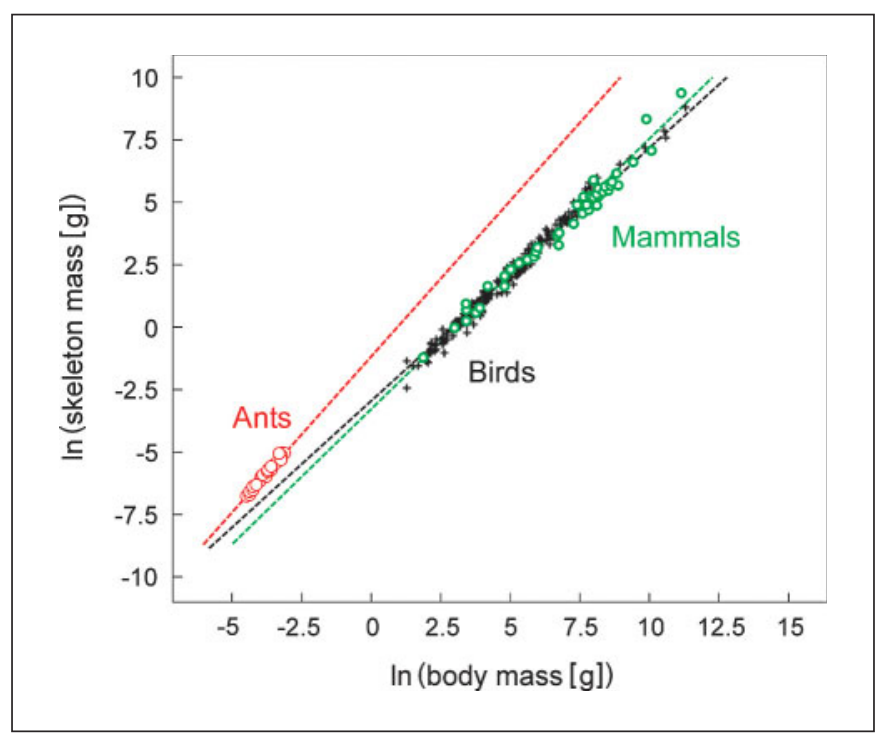

Fig. 3. Skeleton-body mass relationship in ants (exoskeleton) and vertebrates (mammals and birds: endoskeleton). The ant data are based on measurements of the exoskeletons of 27 specimens of two species (Camponotus japonicus, Cataglyphis bicolor), whereas in mammals and birds [Prange et al., 1979] the data points refer to mostly single individuals of 33 and 208 species, respectively. For equations see text.

smaller brains but allometrically larger skeletons than mammals. However, even if the data from ants and mammals are used to compute the brain-soft body size relationships, ant brains are still about ten times smaller than mammalian brains. Estimated from a regression of brain mass to soft body mass, the brain mass of an ant-sized mammal would be about $3.26 \mathrm{mg}$, compared to the 0.28 $\mathrm{mg}$ of the actual mean brain mass of Cataglyphis bicolor.

As an aside, our finding that in ants the scaling exponent of the skeleton-body mass relationship is significantly larger $(b=1.244)$ than 1.0 , and also much larger than in mammals $(b=1.015)$ or birds $(b=1.078)$, lends support to the hypothesis that in insects increases in body size are severely constrained by exoskeleton mass. If insects increased in size beyond what is observed in the real world, their exoskeletons would become disproportionately large.

\section{Discussion}

The main general result of this study is that ants have brains that are small not only in absolute but also in relative terms: the brain of an ant is smaller than the brain of any ant-sized vertebrate would be. Having considered the potentially confounding effect of the insect's exoskeleton-body size relationship (see fig. 3) we can hypothesize that ants have relatively smaller brains than vertebrates because their central nervous system, as that of insects in general, might be less encephalized than the central nervous system of mammals. This notion, however, should not be over-emphasized. The circuitry for locomotor pattern generators (premotor networks) resides in the spinal cord in mammals just as it does in the ventral nerve cord of insects. In terms of numbers of nerve cells in the mammalian brain [Williams and Herrup, 1988] and spinal cord [Kalat, 1998], the ratio of these numbers (brain neurons:spinal-cord neurons) is about 100:1. In insects, comparable numbers are difficult to extract from the literature [Witthöfft, 1967; Strausfeld, 1976; Technau, 1984; Burrows, 1996], but even if the ratio of nerve cells in the brain to nerve cells in the ventral cord were as low as $10: 1$, and one then considered the entire central nervous system (CNS), the allometric CNS-to-body-mass regression line of ants would still lie significantly below those of mammals, birds, and reptiles. This difference might become smaller if one referred to the number of neurons rather than to the weight or volume of the brain. Although there are no fully comparable data available yet, neural density seems to be consistently higher in insects than, for example, in mammals [Strausfeld, 1976]. This would mean that the relatively smaller size of an insect's brain is correlated with a higher degree of miniaturization of neural circuits. Nevertheless, because currently it is almost impossible to decide what would constitute a good measure of information-processing capacity (synaptic architecture, microcircuits, etc.), any remark on 'neural density' would be very speculative indeed. Furthermore, one should not overlook the difference in number and function of glia in the brains of vertebrates and insects, at least, as glia seems to contribute to the greater brain/body mass relationship of vertebrates.

Finally, let us focus on intraspecific aspects. It has been well established, at least in placental mammals [Gould, 1975; Harvey and Bennett, 1983; Bennett and Harvey, 1985; Martin and Harvey, 1985; Pagel and Harvey, 1988] that the scaling exponent for brain-body size relationships decreases with the decreasing rank of the taxonomic category in question. This is the case with our ant data as well. Whereas the scaling exponent for the interspecific comparisons of all formicine species used in the present investigation is $b=0.57$ (fig. 2), the scaling exponents for the intraspecific comparisons are much lower and range from $b=0.203$ to 0.420 (table 2). Within the 
genus Cataglyphis the intraspecific comparisons reveal another and at first glance unexpected result. Even though Cataglyphis is a rather homogenous genus comprising a suite of morphologically quite similar species, two of the five species investigated have significantly smaller brains than the others (fig. 1).

Since the early 1970s Cataglyphis ants have become model systems in the study of animal navigation [Wehner, 2003]. They are solitary foragers, leaving their underground colonies for distances of up to more than one hundred meters while winding their way in a tortuous search for food, and then returning directly to the nest by employing a path integrator [Collett et al., 1999; Wehner and Srinivasan, 2003; Andel and Wehner, 2004] and intricate ways of using view-based landmark information [Wehner et al., 1996]. As shown in figure 1, C. bicolor, C. viatica, and C. mauritanica, that have a sympatric distribution inhabiting the shrub deserts, steppes, and oases of the southern Mediterranean zone, exhibit a similar brain-body size allometric function, whereas the data for C. aenescens (from the grasslands of Mongolia) and $C$. fortis (from the North African salt pans) lie well below those regression lines. Even though at present it is almost impossible to interpret these differences in functional terms, one trait could be functionally correlated with brain size, namely colony size. The colonies of both $C$. aenescens and $C$. fortis comprise only a few hundred individuals, whereas the numbers of nest mates in the colonies of C. bicolor, C. viatica, and C. mauritanica range in the thousands. On the other hand, the above-ground activity patterns of the small-colony species and the largecolony species almost coincide. This applies to temporal parameters such as the number of foraging runs performed by each individual per day and to forager lifetime as well as to the spatial extent of the feeding area occupied by the foragers [Wehner et al., 1983; Schmid-Hempel and Schmid-Hempel, 1984; Schmid-Hempel, 1987]. Actually, C. fortis with its relatively small brain (fig. 1) covers the largest foraging distances [Wehner, 1987]. Hence, we hypothesize that the significantly larger size of the brains in the large-colony species of Cataglyphis - as compared to their small-colony congenerics - is most likely correlated with the social interactions occurring inter-individually within the colony rather than with the outdoor activities of food retrieval and, in this context, navigation. This is in accord with the observation that in all Cataglyphis species studied so far the above-ground activities occupy only the last $20 \%$ of the animal's lifetime [Schmid-Hempel and Schmid-Hempel, 1984]. Furthermore, given the high energy demands for development and operation of the brain, larger colonies might somehow be able to provide greater availabilities for energy.

Returning to ant brain allometry in general, at least three major conclusions can be drawn from the present study. First, the most general conclusion is that allometric brain-body size relationships, which have been documented and discussed so intensively in vertebrates especially in mammals, apply to insects as well. In the miniature brains of ants, the allometric scaling exponent is also significantly smaller than 1.0, meaning that the smaller the animal, the larger the proportional size of its brain. Hence, this type of allometric correlation exists in widely separated phylogenetic lines comprising animals of extremely different body sizes. This implies that, if age-dependant or task-related volumetric changes of particular neuropiles of insect brains were studied across cohorts of animals of different body sizes, allometric relationships between neuropil size and body size should always be taken into account. Second, but stated more cautiously, the allometric scaling exponent found for ants $(b=0.57)$ is similar to the values obtained for reptiles $(b=0.54)$ and birds $(b=0.58)$, but significantly smaller than the scaling exponent in mammals $(b=0.77)$. Both conclusions are based on appropriate and robust methods of computing allometric functions (rotation line) applied by us to our own data sets (for ants) and to data sets taken from the literature (for vertebrates). Furthermore, even if the phylogenetic relationships among the species considered in our ant brain analyses are taken into account, the scaling exponent is very similar indeed $(b=0.539)$. Hence, the allometric brain-body size relationship is not an artifact caused by phylogenetic effects [Pagel, 1992; Martin, 1996]. Third, and most importantly, the scaling coefficient 'a' of the allometric brain-body size equation is significantly smaller in ants than it is in mammals, birds and reptiles, implying that in ants the brains are relatively smaller, as compared to body size, than they are in vertebrates.

\section{Acknowledgements}

We thank Professor Robert D. Martin (Field Museum, Chicago) for many stimulating discussions, Dr. Markus Knaden for the mtDNA analyses, and Dr. Ursula Menzi for editorial expertise. Financial support came from the Swiss National Science Foundation, grant No. 31-61844. 


\section{References}

Andel D, Wehner R (2004) Path integration in desert ants, Cataglyphis: how to make a homing ant run away from home. Proc R Soc Lond B Biol Sci 271:1485-1489.

Anderson JF, Rahn H, Prange HD (1979) Scaling of supportive tissue mass. Q Rev Biol 54:139148.

Barth M, Heisenberg M (1997) Vision affects mushroom bodies and central complex in Drosophila melanogaster. Learn Mem 4:219229.

Bennett PM, Harvey PH (1985) Relative brain size and ecology in birds. J Zool 207:151169.

Benton MJ, Ayala FJ (2003) Dating the tree of life. Science 300:1698-1700.

Boire D, Baron G (1994) Allometric comparison of brain and main brain subdivisions in birds. J Brain Res 35:49-66.

Brown SM, Napper RM, Mercer AR (2004) Foraging experience, glomerulus volume, and synapse number: A stereological study of the honey bee antennal lobe. J Neurobiol 60:4050.

Burrows M (1996) The Neurobiology of an Insect Brain. Oxford, UK: Oxford University Press.

Chen JY, Bottjer DJ, Oliveri P, Dornbos SQ, Gao F, Ruffins S, Chi HM, Li CW, Davidson EH (2004) Small bilaterian fossils from 40 to 55 million years before the Cambrian. Science 305:218-222.

Collett M, Collett TS, Wehner R (1999) Calibration of vector navigation in desert ants. Curr Biol 9:1031-1034.

Connolly JB, Roberts IJH, Armstrong JD, Kaiser K, Forte M, Tully T, Okane CJ (1996) Associative learning disrupted by impaired G(s) signaling in Drosophila mushroom bodies. Science 274:2104-2107.

Count EW (1947) Brain and body weight in man - their antecedents in growth and evolution - a study in dynamic somatometry. Ann NY Acad Sci 46:993-1122.

Crile GW, Quiring DP (1940) A record of the body weights and certain organ and gland weights of 3690 animals. Ohio J Sci 40:219259.

Durst C, Eichmuller S, Menzel R (1994) Development and experience lead to increased volume of subcompartments of the honeybee mushroom body. Behav Neural Biol 62:259263.

Ehmer B, Gronenberg W (2004) Mushroom body volumes and visual interneurons in ants: Comparison between sexes and castes. J Comp Neurol 469:198-213.

Ehmer B, Reeve HK, Hoy RR (2001) Comparison of brain volumes between single and multiple foundresses in the paper wasp Polistes dominulus. Brain Behav Evol 57:161-168.
Fahrbach SE, Farris SM, Sullivan JP, Robinson GE (2003) Limits on volume changes in the mushroom bodies of the honey bee brain. J Neurobiol 57:141-151.

Fahrbach SE, Moore D, Capaldi EA, Farris SM, Robinson GE (1998) Experience-expectant plasticity in the mushroom bodies of the honeybee. Learn Mem 5:115-123.

Farris SM, Robinson GE, Fahrbach SE (2001) Experience- and age-related outgrowth of intrinsic neurons in the mushroom bodies of the adult worker honeybee. J Neurosci 21: 6395-6404.

Felsenstein J (1985) Phylogenies and the comparative method. Am Nat 125:1-15.

Goossen H (1949) Untersuchungen an Gehirnen verschieden grosser, jeweils verwandter Coleopteren- und Hymenopteren-Arten. Zool Jb Allg Zool 62:1-64.

Gould SJ (1975) Allometry in primates, with emphasis on scaling and evolution of brain. Contrib Primatol 5:244-292.

Gronenberg W (1987) Anatomical and physiological properties of feedback neurons of the mushroom bodies in the bee brain. Exp Biol 46:115-125.

Gronenberg W, Holldobler B (1999) Morphologic representation of visual and antennal information in the ant brain. J Comp Neurol 412:229-240.

Gronenberg W, Liebig J (1999) Smaller brains and optic lobes in reproductive workers of the ant Harpegnathos. Naturwissenschaften 86:343-345.

Gronenberg W, Heeren S, Holldobler B (1996) Age-dependent and task-related morphological changes in the brain and the mushroom bodies of the ant Camponotus floridanus. J Exp Biol 199:2011-2019.

Harvey PH, Bennett PM (1983) Brain size, energetics, ecology and life-history patterns. Nature 306:314-315

Harvey PH, Pagel MD (1991) The Comparative Method in Evolutionary Biology. Oxford, UK: Oxford University Press.

Heisenberg M (1998) What do the mushroom bodies do for the insect brain? An introduction. Learn Mem 5:1-10.

Hildebrand M, Goslow GE (2001) Analysis of Vertebrate Structure. New York: John Wiley.

Hölldobler B, Wilson EO (1990) The Ants. Cambridge, MA: Harvard University Press.

Isler K, Barbour AD, Martin RD (2002) Line-fitting by rotation: A nonparametric method for bivariate allometric analysis. Biometrical J 44:289-304.

Jaffe K, Perez E (1989) Comparative study of brain morphology in ants. Brain Behav Evol 33:25-33.

Jerison HJ (1973) Evolution of the Brain and Intelligence. New York: Academic Press.

Kalat JW (1998) Biological Psychology. Pacific Grove: Brooks/Cole Publishing Co.
Kern MJ (1985) Metabolic rate of the insect brain in relation to body size and phylogeny. Comp Biochem Physiol A Physiol 81:501-506.

Kleiber M (1961) The Fire of Life: An Introduction to Animal Energetics. New York: John Wiley.

Korr H (1968) Das postembryonale Wachstum verschiedener Hirnbereiche bei Orchesella villosa (Insecta, Collembola). Z Morph Tiere 62:389-422.

Kuehn-Buehlmann S, Wehner R (2006) Age-dependent and task-related volume changes in the mushroom bodies of visually guided desert ants, Cataglyphis bicolor. J Neurobiol 66: 511-521.

Li YS, Strausfeld NJ (1997) Morphology and sensory modality of mushroom body extrinsic neurons in the brain of the cockroach, Periplaneta americana. J Comp Neurol 387:631650

Martin RD (1981) Relative brain size and basal metabolic rate in terrestrial vertebrates. $\mathrm{Na}$ ture 293:57-60.

Martin RD (1983) Human Brain Evolution in an Ecological Context. New York: American Museum of National History.

Martin RD (1996) Scaling of the mammalian brain: The maternal energy hypothesis. News Physiol Sci 11:149-156.

Martin RD, Barbour AD (1989) Aspects of linefitting in bivariate allometric analyses. Folia Primatol 53:65-81.

Martin RD, Harvey PH (1985) Brain size allometry: ontogeny and phylogeny. In: Size and Scaling in Primate Biology (Jungers WL, ed), pp 147-173. New York: Plenum Press.

Neder R (1959) Allometrisches Wachstum von Hirnteilen bei drei verschieden grossen Schabenarten. Zool Jb Anat 77:411-464.

Nielsen C (2001) Animal Evolution: Interrelationships of the Living Phyla. Oxford, UK: Oxford University Press.

O'Donnell S, Donlan NA, Jones TA (2004) Mushroom body structural change is associated with division of labor in eusocial wasp workers (Polybia aequatorialis, Hymenoptera : Vespidae). Neurosci Lett 356:159-162.

Pagel MD (1993) Seeking the evolutionary regression coefficient: An analysis of what comparative methods measure. J Theor Biol 164:191-205.

Pagel MD (1992) A method for the analysis of comparative data. J Theor Biol 156:431442

Pagel MD, Harvey PH (1988) The taxon-level problem in the evolution of mammalian brain size - facts and artifacts. Am Nat 132: 344-359.

Peterson KJ, Lyons JB, Nowak KS, Takacs CM, Wargo MJ, McPeek MA (2004) Estimating metazoan divergence times with a molecular clock. Proc Natl Acad Sci USA 101:65366541 
Platel R (1976) Analyse volumétrique comparée des principales subdividions encéphaliques chez les reptiles sauriens. J Hirnforsch 17: 513-537.

Portmann A (1947) Etudes sur la cérébralisation chez les oiseaux. II. Les indices intra-cérébraux. Alauda 15:1-15.

Prange HD, Anderson JF, Rahn H (1979) Scaling of skeletal mass to body mass in birds and mammals. Am Nat 113:103-122.

Purvis A, Rambaut A (1995) Comparative analysis by independent contrasts (CAIC): an Apple Macintosh application for analysing comparative data. Comput Appl Biosci 11: 247-251.

Reichert H, Simeone A (1999) Conserved usage of gap and homeotic genes in patterning the CNS. Curr Opin Neurobiol 9:589-595.

Schmid-Hempel P (1987) Foraging characteristics of the desert ant Cataglyphis. Experientia Suppl 54:43-61.

Schmid-Hempel P, Schmid-Hempel R (1984) Life duration and turnover of foragers in the ant Cataglyphis bicolor (Hymenoptera, Formicidae). Insect Soc 31:345-360.

Sharman AC, Brand M (1998) Evolution and homology of the nervous system: cross-phylum rescues of otd/Otx genes. Trends Genetics $14: 211-214$
Stephan H, Bauchot R, Andy O (1970) Data on size of the brain and various brain parts in insectivores and primates. In: The Primate Brain (Nobak CR, Montagna W, eds), pp 289-297. New York: Appleton.

Stephan H, Nelson JE, Frahm HD (1981) Brain size comparison in Chiroptera. Z Zool Syst Evol-forsch 19:195-222.

Strausfeld NJ (1976) Atlas of an Insect Brain. Berlin: Springer.

Strausfeld NJ (2001) Insect brain. In: Brain, Evolution and Cognition (Roth G, Wullimann MF, eds), pp 367-400. New York: John Wiley.

Strausfeld NJ, Hansen L, Li YS, Gomez RS, Ito K (1998) Evolution, discovery, and interpretations of arthropod mushroom bodies. Learn Mem 5:11-37.

Taylor CR, Heglund NC, Maloiy GMO (1982) Energetics and mechanics of terrestrial locomotion. 1. Metabolic energy-consumption as a function of speed and body size in birds and mammals. J Exp Biol 97:1-21.

Technau GM (1984) Fiber number in the mushroom bodies of adult Drosophila melanogaster depends on age, sex and experience. J Neurogenet 1:113-126.

von Bonin G (1937) Brain-weight and bodyweight of mammals. J Gen Psych 16:379389.
Wehner R (1987) Spatial organization of foraging behavior in individually searching desert ants, Cataglyphis (Sahara desert) and Ocymyrmex (Namib desert). Experientia Suppl 54:15-42.

Wehner R (2003) Desert ant navigation: how miniature brains solve complex tasks. J Comp Physiol (A) 189:579-588.

Wehner R, Harkness R, Schmid-Hempel P (1983) Foraging Strategies in Individually Searching Ants, Cataglyphis bicolor. Stuttgart: Fischer.

Wehner R, Michel B, Antonsen P (1996) Visual navigation in insects: Coupling of egocentric and geocentric information. J Exp Biol 199: 129-140.

Wehner R, Srinivasan MV (2003) Path integration in insects. In: Biological Basis of Navigation (Jeffery K, ed), pp 9-30. Oxford, UK: Oxford University Press.

Williams NA, Holland PWH (1998) Molecular evolution of the brain of chordates. Brain Behav Evol 52:177-185.

Williams RW, Herrup K (1988) The control of neuron number. Ann Rev Neurosci 11:423453.

Witthöft W (1967) Absolute Anzahl und Verteilung der Zellen im Hirn der Honigbiene. Z Morph Tiere 61:160-184. 